\title{
A 100-Year Review: Animal welfare in the Journal of Dairy Science-The first 100 years $^{1}$
}

\author{
Marina A. G. von Keyserlingk ${ }^{2}$ and Daniel M. Weary \\ Animal Welfare Program, Faculty of Land and Food Systems, University of British Columbia, Vancouver, V6T 1Z4, Canada
}

\begin{abstract}
This paper outlines the history and development of research in the area of animal welfare as reflected in the 100 yr that the Journal of Dairy Science has been published. The first paper using the term "animal welfare" was published in 1983; since then (to May 2017), 244 papers that reflect growing interest regarding how farm animals are cared for have been published. Much of the scientific work to date has focused on issues related to cow health, such as lameness, and methodologically many papers use behavioral measures. In addition to this science-based research, the journal has taken on the role of publishing work of social scientists that addresses the role of the human factors relating to animal welfare, including research on citizen, consumer, and farmer attitudes toward welfare issues. We call for further research focused on societal perspectives and for new biological research focused on developing issues, such as cow-calf separation and pasture access.
\end{abstract}

Key words: animal well-being, animal care, animal behavior, animal rights

\section{INTRODUCTION}

This review outlines the history and development of scholarly work on the topic of animal welfare as reflected in the 100 yr that the Journal of Dairy Science (JDS) has been published. Coverage of this topic has expanded dramatically over the past $30 \mathrm{yr}$, with the greatest expansion occurring very recently. Animal welfare is an area of application rather than a discipline and is amenable to a variety of disciplinary approaches, including physiology, genetics, nutrition, sociology, and so on. Animal behavior has been an especially useful disciplinary approach to welfare questions, but behavioral studies also address more basic issues (e.g., the nature of social relationships) and practical issues (e.g.,

Received June 6, 2017.

Accepted July 27, 2017.

${ }^{1}$ This review is part of a special issue of the Journal of Dairy Science commissioned to celebrate 100 years of publishing (1917-2017).

${ }^{2}$ Corresponding author: marina.vonkeyserlingk@ubc.ca heat detection) that are not related to animal welfare. In the current paper we focus on animal welfare but highlight how the field of animal behavior has played a role in finding solutions to improve dairy cattle welfare.

In the sections that follow, we define what we mean by animal welfare and the types of concerns that it encompasses, provide a brief history of animal welfare as a social movement, and focus on how animal welfare issues have been addressed within JDS, identifying how far we have come and key papers where possible. We end with our vision for how research in dairy welfare will continue to develop in the years to come.

\section{What is Animal Welfare?}

The study of welfare is focused on improving the lives of animals, but exactly what this means has changed over the past century. Traditionally, a good life has been associated with good health and appropriate levels of production, but scholars working on health or production might not think of themselves as working on welfare. Although both health and production are associated with good biological functioning on the part of the animal, sometimes the methods used to address health and production goals may introduce other types of welfare concerns.

A more modern view of welfare concerns how the animal feels (Duncan, 2004); this view would support changing procedures to minimize negative affective states (e.g., pain) and promote positive states (e.g., pleasure). The main challenge with this approach is scientific, and much research has been devoted to developing and validating methods to assess emotional states in animals (Weary et al., 2017). Some authors have also argued that allowing animals to live reasonably natural lives (e.g., providing the ability to express natural behaviors such as drinking milk through a nipple in calves) is also an important dimension to animal welfare, explaining why some standards require access to more natural environments (e.g., pasture) or the ability to perform key behaviors (e.g., the cow nursing her calf).

In 1997, David Fraser and colleagues published a conceptual paper calling for the integration of all 3 
approaches (biological functioning, natural behavior, and affective states), arguing that welfare problems can emerge in any of these 3 areas and that the best practices will address all 3 areas of concern (Fraser et al., 1997). These arguments were specifically applied to dairy cattle in a review by von Keyserlingk et al. (2009), where it was argued, for example, that allowing cows to seek shade on a hot day (natural behavior) will help prevent the cow from feeling uncomfortably hot (affective state) and reduce the health and production risks associated with heat stress (biological functioning). According to this framework, it would be misguided to address one type of welfare concern (e.g., high rates of enteric and respiratory infections in dairy calves - a biological functioning concern) by imposing a solution that introduces new welfare concerns around natural living and affective state (e.g., the use of individual housing that prevents natural interactions and play).

Animal welfare is an ethical concept and is subject to societal input. Progress on welfare relies on science, in part to provide evidence that can aid in the process of consensus building between the various stakeholders, but this scientific work must not occur in a vacuum. The science should instead be grounded in an understanding of societal values that help identify issues and anticipate objections to new practices (Weary et al., 2016).

\section{Animal Welfare as a Social Movement}

Criticisms relating to the standard industry practices associated with the care and handling of farm animals first entered the mainstream media in the mid-1960s following publication of the book Animal Machines (Harrison, 1964). This book described housing and production practices for laying hens, broiler birds, and veal calves and highlighted the unnaturalness (i.e., lack of sunshine, fresh air, and space) of these systems. The negative reaction by the British public motivated the UK government to commission the report titled "Report of the Technical Committee to Enquire into the Welfare of Animals Kept Under Intensive Livestock Husbandry Systems" (Brambell, 1965). This report argued that animals should have the freedom "to stand up, lie down, turn around, groom themselves and stretch their limbs" and that many of the standard systems for rearing farm animals were morally unacceptable.

The findings of the Brambell (1965) report were used to develop the Five Freedoms by the Farm Animal Welfare Council (FAWC, 1992): (1) freedom from thirst and hunger; (2) freedom from discomfort; (3) freedom from pain, injury, and disease; (4) freedom to express normal behavior; and (5) freedom from fear and distress. Similar events have taken place in other coun- tries. Most notably, Sweden passed animal welfare laws in 1988 effectively banning zero-grazing systems for dairy cattle (Ministry for Rural Affairs - Government Offices of Sweden, 2009). The European Union has promoted farm animal welfare, announcing within its first directive in 1991 that, among other things, focus must be placed on care and housing of dairy calves (for additional discussion see von Keyserlingk and Hötzel, 2015).

At the time of publication of Animal Machines (Harrison, 1964), only 2 federal laws in the United States regulated the treatment of farm animals. The TwentyEight Hour Law (USDA, 1873), passed to protect livestock during transport to slaughter, required that after $28 \mathrm{~h}$ of travel in the United States by rail, steam, sail, or "vessels of any description," livestock must be unloaded and provided feed, water, and a resting area for a minimum of 5 consecutive hours before resuming transport. The Humane Methods of Slaughter Act (USDA, 1958) required that livestock must be rendered insensible before slaughter (see also Mench, 2008). More recently, a number of farm animal welfare laws have been enacted at the state level within the United States. The first of these was enacted in Florida in 2008, resulting in a ban on gestation stalls for sows. Since then, 9 states have effectively banned a variety of standard industry practices. A particularly well-known example is the 2008 California ballot initiative (Proposition 2) that, effective January 1, 2015, required that "calves raised for veal, egg-laying hens, and pregnant pigs be confined only in ways that allow these animals to lie down, stand up, fully extend their limbs, and turn around freely." The passing of Proposition 2 in California resulted in additional consequences. Senate bill 135, dated October 11, 2009, made an amendment to section $597 \mathrm{n}$ of the penal code, relating to animal abuse, that specifically banned tail docking of cattle (California Legislative Information, 2009).

These types of legislative changes have driven industry-led responses, including the development of guidance documents for farmers and verification procedures to provide assurance that farms are meeting these guidelines. In Canada this process has been led by the Dairy Farmers of Canada and Canada's National Farm Animal Care Committee (NFACC, 2014), who have worked together to create a code of practice for the care and handling of dairy cattle (DFC-NFACC, 2009). The US counterpart was led by the National Milk Producers Federation, who published the first version of the Farmers Assuring Responsible Management (FARM) program in 2009; this document has gone through 2 substantive revisions since then (NMPF, 2016). Whether these industry-led approaches will provide the necessary assurances to the public is unknown. 
However, as we have previously highlighted (see Weary and von Keyserlingk, 2017), these types of standards are likely to be challenged in at least 2 ways: (1) there will likely be pressure from within the industry to have standards sufficiently lax to enable almost all farms to comply but, (2) there will likely be external pressure to maintain a supply chain that does not include bad actors (see Weary and von Keyserlingk, 2017; Wolf and Tonsor, 2017).

The North American dairy industry seems to be unwilling to leave the issue of animal welfare solely to farmer-run organizations. Both Dean Foods Inc. (2012) and Saputo Inc. (2015) have shown a willingness to play a major role in driving change for improved welfare on dairy farms. For example, in its animal welfare policy, Saputo Inc. (2015) states that it has "zero tolerance for any act of animal cruelty" and requires "compliance with codes/standards for proper animal care and handling." Saputo Inc. also calls on the industry to eliminate or modify routine management practices that are unnecessary or cause pain and makes specific reference to tail docking and the use of pain mitigation when dehorning or disbudding.

\section{ANIMAL WELFARE WITHIN JDS}

We conducted a systematic search of the published literature addressing animal welfare in JDS using Web of Science to search for the specific keywords "animal" and "welfare" or "animal" and "well-being" in the title, abstract, or key words of published articles and reviews from 1917 until May 2017: SO = (JOURNAL OF DAIRY SCIENCE) AND TS $=(($ animal AND (wellbeing OR well-being OR "well being") OR (animal welfare)). This search identified 244 papers; 228 papers were identified using the search term "animal" and "welfare," and an additional 16 papers were identified when "animal well-being" was included. Although the current review is focused on publications appearing in JDS, much research on the welfare of dairy animals also appears in other journals, most notably Animal Welfare and Applied Animal Behaviour Science. We refer interested readers to these and other journals for additional papers in this subject area.

The timeline provided in Appendix Table A1 highlights some of the key papers in relation to key events that have helped shape the field of animal welfare. The terms "animal" and "welfare" first appeared in JDS in 1983 in an Our Industry Today article authored by the noted researcher Jack Albright (1983). In a forwardthinking approach to this topic, the journal published in the same issue a paper by animal advocate Michael Fox (1983). These 2 papers (plus another written 4 yr later; Albright, 1987) are still recommended reading, in part because they provide a clear list of welfare research topics, many of which are still relevant today.

In the 1990s JDS published very little on the topic of animal welfare, but the relevant number of publications has increased rapidly since the turn of the new millennium (Figure 1). By 2009 a total of 50 papers on some aspect of dairy welfare had been published. By 2012, 100 papers had been published, and as of May 2017, 244 papers had been published.

To illustrate the variety of issues and methods addressed in these 244 papers, we generated a word cloud illustrating the most common words that appeared in these papers (Figure 2). As discussed above, behavioral studies have played a key role in welfare research, so it is not surprising that "behavior" is the largest word in the cloud and that words describing specific behaviors (lying, feed, and locomotion) are also prominent. Also, given that good health has long been considered an important element of good welfare, it not surprising to see that the word "health" is larger than any of the other issue-type words appearing. This also explains why related words (e.g., lameness, disease, mastitis, lesions, prevalence, clinical) are also prominent.

\section{Health as a Welfare Concern}

Although the word "animal welfare" is used only in more recent papers, dairy scientists have long been interested in maintaining and improving animal health, even though this has not necessarily been explicitly linked to welfare. Using the same search methodology described earlier, we found that the first paper to use the term "health" appeared in JDS in 1945 (Seath et al., 1945). Since then, this term has appeared in more than 1,800 papers, including in many relevant articles, such as the reviews on transition cow health by Drackley (1999) and LeBlanc et al. (2006). Only more recently have authors specified a link between good health and good welfare. The first time "animal" and "welfare" or "animal" and "well-being" appeared in our search was in Wells et al. (1998). These 2 terms have since appeared together in a total of 118 papers (as of May 2017), suggesting that a more explicit linkage is now important.

\section{Affective States as Welfare Concerns}

Welfare often emphasizes the animal's affective state (including negative experiences such as fear, pain, and hunger). Pain appears in our word cloud, as do the painful procedures dehorning and disbudding as well as painful ailments such as lameness, injuries, and dystocia. The first paper using the word "pain" appeared in JDS in 1999 in a paper related to mastitis (Hoeben et 
al., 1999); in this case the authors were using clinical signs of pain as an outcome measure for their study, but they clearly link infection to pain. Earlier papers may have discussed pain in the body of the paper even though the word did not appear in the sections of the paper that were covered by our search criteria. For example, the first paper with the word "dehorning" appeared in 1994 (Wohlt et al., 1994). These authors did not use "pain" in the title, abstract, or key words but did discuss pain in relation to studies on humans. Pain is now recognized as an important issue in dairy cattle welfare - for example, as related to disbudding (Faulkner and Weary, 2000), tail docking (Eicher et al., 2000), and dystocia (Barrier and Haskell, 2011). Since 1999 more than 70 papers using the word "pain" have been published in JDS.

Another affective state with relatively unambiguous welfare connotations is fear. The word "fear" fails to appear in the word cloud, showing that little research has been published on this topic. Indeed, our search found only 13 papers using this term in JDS. Of these, the first published was titled "Discrimination of People by Dairy Cows Based on Handling" (Munksgaard et al., 1997). The ideas that animal handling methods may contribute to fearfulness and that fear responses can be used to improve handling procedures are important for JDS to consider.

Other negative affective states are considered in a few papers, although connotations for animal welfare are not always clear. For example, the term "hunger" first appears in a paper in 1971, but this study ("Hormones and Amino Acids as Possible Factors in Control of Hunger and Satiety in Sheep"; Baile and Martin, 1971) did not specifically consider hunger as a negative emotional state or its relevance to animal welfare. More recently, hunger has been treated as an important welfare concern, with a special focus on problems associated with underfeeding of the preweaned calf (reviewed by Khan et al., 2011).

Although much of the welfare-relevant work on affective states has focused on negative states such as those discussed above, more recent work in the field has also considered positive emotional states (for review see Boissy et al., 2007). Although play is a behavior rather than an emotional state, many have argued that the presence of play is indicative of a positive emotional state. Play is more common in young animal than in adults, and papers published to date on play have all

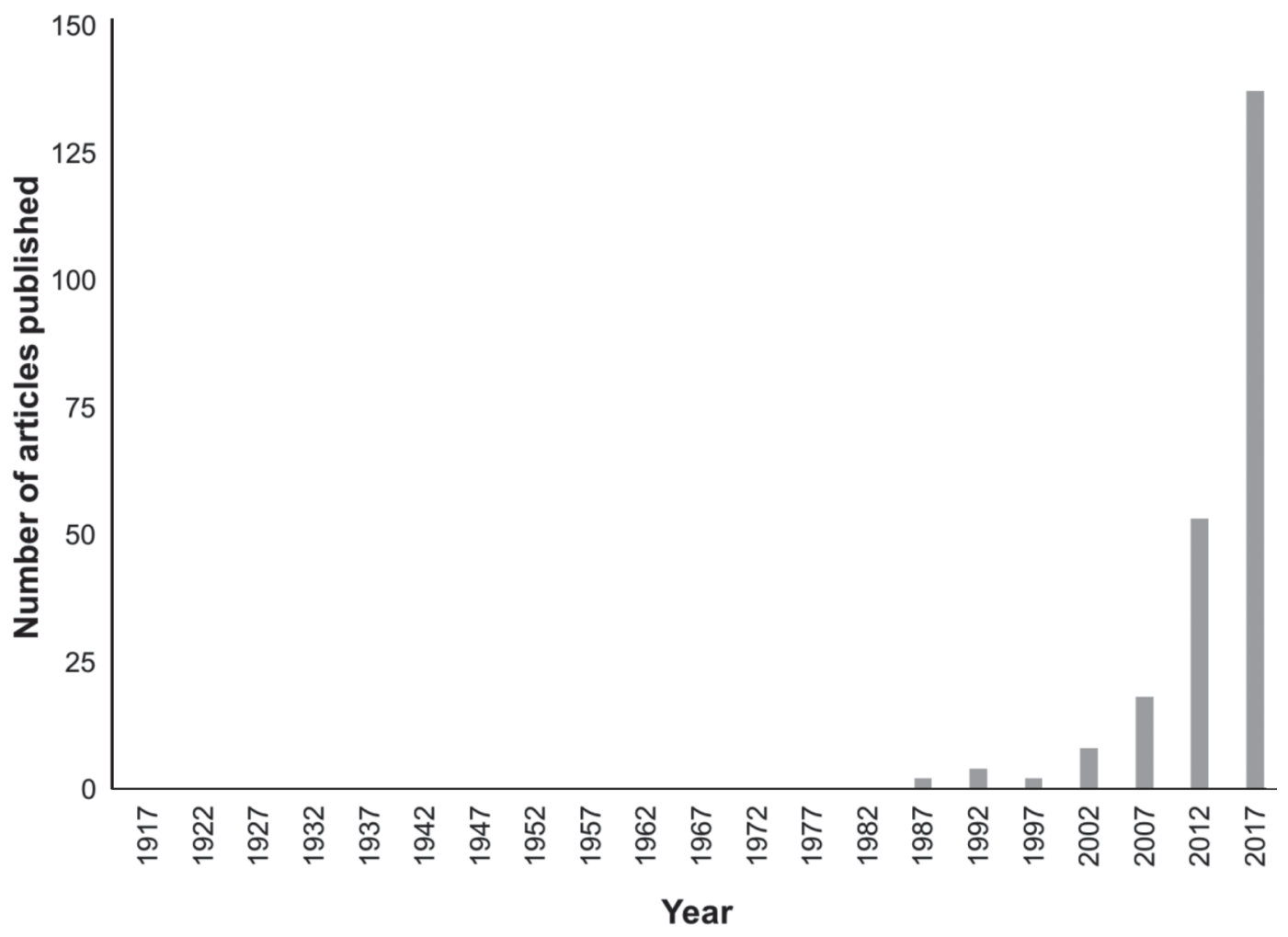

Figure 1. The number of papers published on the topic of animal welfare as reflected in the 100 yr that the Journal of Dairy Science (JDS) has been published (1917-May 2017) with the words "animal" and "welfare" or "animal" and "well-being" in the title, abstract, or key words. Results are shown by 5-yr periods (i.e., 1917-1922, 1923-1927, and so on). The first paper meeting these search criteria appeared in 1983; a total of 244 papers have appeared in JDS as of the time this review was written. 


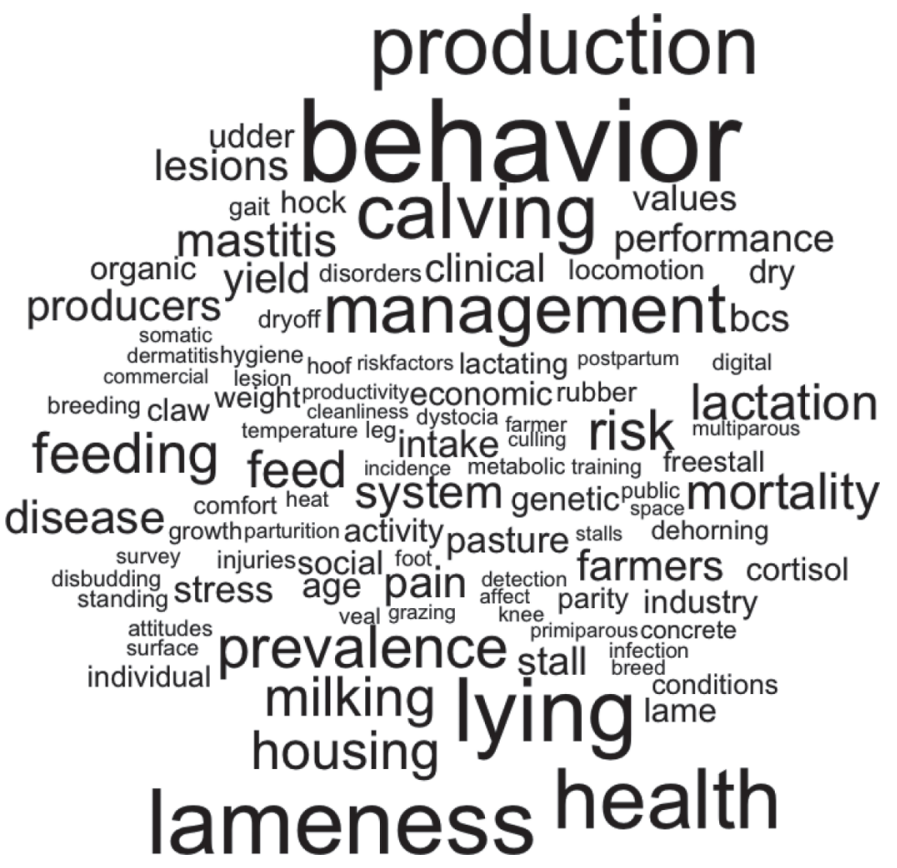

Figure 2. A word cloud generated using the titles, abstracts, and key words of the 244 papers resulting from our search of papers published in the Journal of Dairy Science between 1983 and the time this review was written (May 2017). The cloud shows the 100 most commonly appearing words related to animal welfare; those appearing in larger type are used more frequently. The most common word was "behavior" (appearing 334 times), and the least common word was "weaning" (appearing just 28 times)

focused on calves. For example, a recent JDS paper from the Czech Republic ("The Effect of Age at Separation from the Dam and Presence of Social Companions on Play Behavior and Weight Gain in Dairy Calves"; Valníčková et al., 2015) showed that play behavior is more common when calves are housed socially versus individually, suggesting that social housing allows for more positive affective states in these animals. We encourage more work on positive states in the years to come.

The term "stress" has some relevance to animal welfare. For example, painful experiences are often accompanied by characteristic physiological responses (e.g., the spike in serum cortisol typically observed in the hours after disbudding; Heinrich et al., 2009). However, physiological stress responses can accompany neutral or even positive experiences, making it difficult to draw clear welfare inferences from these physiological responses. More than 700 papers using the word "stress" have appeared in JDS, but many of these did not explicitly address welfare. We found only 37 papers with both "stress" and "animal welfare"; the first was a review by Ingvartsen and Andersen (2000) titled "Integration of Metabolism and Intake Regulation: A
Review Focusing on Periparturient Animals." The first empirical paper using these terms, published in 2002 (Schreiner and Ruegg, 2002), addressed behavioral and physiological responses to tail docking in calves and heifers.

\section{Naturalness as a Welfare Concern}

The third sphere of concern, according to the framework of Fraser et al. (1997), is natural living; this includes the animal's ability to access reasonably natural environments and to perform natural behaviors that they are motivated to perform. In many ways this is the most problematic of the 3 spheres. Some authors argue that aspects of natural living are inherent to definitions of a good life in animals (e.g., Fraser et al., 1997), but others argue that natural living is only important in that it improves the animal's affective state (Dawkins, 1988). The natural criterion also may seem awkward for those who see their responsibility as maintaining a managed system rather than a natural one, including the protection of animals from natural risks such as predation, parasite infection, and climatic extremes. That said, concerns about naturalness are deeply rooted in traditional thinking about dairy systems. For example, some of the earliest papers in JDS addressed the issue of providing calves more naturalistic opportunities to ingest milk. In the words of Wise and Anderson (1939), "The unthrifty appearance commonly observed in young dairy calves in modern dairy herds has been attributed, in many cases, to the deviation from 'nature's way' of feeding." We found only 18 papers with both "natural*" and "animal welfare/animal wellbeing"; the first time that these 2 terms were mentioned together was in a review article by Albright (1993) titled "Feeding Behavior of Dairy Cattle." As we argue below, public conceptions of welfare often focus more on natural living aspects, and we hope that future JDS publications will increasingly consider these measures.

To some degree, the presence of abnormal behaviors, including the repetitive and apparently functionless stereotypic behaviors, can be seen as the antithesis of the natural living ideal. Thus, what is unnatural serves to remind us of what is natural, and it is sometimes argued that abnormal behaviors are the result of housing animals in unnatural environments that fail to meet their needs (Mason, 2008). A few papers published in JDS have addressed abnormal $(\mathrm{n}=3)$ and stereotypic $(\mathrm{n}=6)$ behaviors. One example, authored by a group of Dutch researchers, examined risk factors for nonnutritive oral behaviors (e.g., tongue rolling) on commercial veal farms (Leruste et al., 2014). Clearly more work is required in this area. 


\section{An Issue-By-Issue Approach}

In addition to considering the literature from the perspective of the 3 spheres, we can consider papers on an issue-by-issue basis (e.g., overstocking). The list of potential welfare issues to be considered is long, but relatively few specific issues have been addressed in more than just a handful of papers in JDS. A few of the bestresearched examples have been featured in curated "top 10 " lists of papers appearing in the "Collections" section of the JDS website (http://www.journalofdairyscience .org/collections). Specifically regarding animal welfare, collections are currently available featuring disbudding and pain management for calves (the first published being Faulkner and Weary, 2000), stocking density (the first published being Huzzey et al., 2006), and tail docking (the first published being Eicher et al., 2000). We encourage future additions to the collections on welfare-relevant topics, including limit feeding of calves, social housing for calves, heat stress for lactating cows, and pasture access for cows, to name a few.

\section{Social Science Contributions}

Animal welfare is an important social concern and one of several issues (e.g., environmental, social justice) that need to be addressed to keep industry practices in line with evolving community standards. Unlike some areas of dairy science in which only scientific expertise is required, socially mandated research requires input and interplay between the science and the society that frames the issues. Sometimes this input can happen informally, via discussions with neighbors and others, but a more systematic approach is to turn the social questions into an important research agenda in their own right. Research undertaken in the social sciences can aid us in understanding the attitudes of different stakeholders, including people who work within the dairy industry (e.g., farmers, veterinarians, dairy industry specialists) and those who are not affiliated with the industry (e.g., the customer who buys milk at the grocery store, the neighbor to the dairy). Research in social sciences allows us to identify contentious topics as well as areas of agreement and thus plays a role in efforts to harmonize industry practices with societal expectations (Weary et al., 2016). Journal of Dairy Science has shown remarkable openness in publishing work using social science methodologies. Indeed, the word cloud includes the term "attitudes," illustrating the volume of work that has been published describing stakeholder views relevant to animal welfare. This work is still very recent. The first example appeared in 2008; this study described the reactions of citizens in a Vermont community in which a local dairy farm had recently expanded from about 225 cows to 684 cows (Smith et al., 2008). This study was important in that it documented community concerns associated with large farms, including perceived negative effects on the environment (including water quality) and animal welfare. This type of research can help identify needs for future research that addresses these concerns.

One example where JDS has made a particular contribution is in the area of pasture access. Several social science papers have shown that the public considers access to pasture to be important to the welfare of dairy cows both in the United States (i.e., Cardoso et al., 2016) and elsewhere (i.e., Brazil; Hötzel et al., 2017). Interestingly, there is evidence that farmers also consider pasture to be important to cattle (Schuppli et al., 2014). This same work showed that farmers perceive a lack of ability to provide pasture to their cows - for example, because of a lack of land or because of unfavorable climatic conditions. Journal of Dairy Science has published a series of studies showing that cows preferentially use pasture at night but stay indoors during the day (e.g., Charlton et al., 2011). One reason why cows prefer to remain indoors during the day is that higher energy total mixed diets are typically provided indoors, and feed intake is highest during daylight hours (DeVries et al., 2003). These studies illustrate the potential of hybrid systems that allow cows to go to pasture but also maintain access to a well-designed barn and mixed ration. This serves as an example of the how research in the biological and social sciences can work in harmony.

Scientific work of this nature may not always adequately address the societal concern, and societal concerns can evolve just as quickly as the science. Thus, the science that leads to developing new approaches needs to happen together with the social science research that seeks to document and understand the underlying concerns. Ideally, this may form a type of feedback loop going from the social science to the science and back again.

\section{HOW FAR HAVE WE COME?}

To get a sense of the progress we have seen in animal welfare research published in JDS, we return to research priorities summarized in the pioneering papers of Albright (1983) and Fox (1983). This process shows that in some areas we have made considerable strides, whereas in other cases much remains to be done.

Albright (1983) lists several items in his "Future Research and Solutions" section (p. 66), including confinement housing, (i.e., concrete flooring), different stall types, overstocking and group size, and, more broadly, cow comfort in different housing systems. More specific 
concerns included the use of crowd gates in the milking parlor and behavioral problems such as cross-sucking in calves.

The issue of cow comfort has received considerable coverage in JDS. This line of research has addressed topics such as stocking density (as mentioned above), the effects of various flooring options on cow health (Somers et al., 2003) and behavior (Telezhenko et al., 2007,2008 ), and the effect of lying surface on preferences for freestalls (Natzke et al., 1982). We note that little work has contrasted cow comfort in different housing systems, but we also caution readers that wellreplicated studies assessing system-level differences are difficult to achieve. We also could find no research published in JDS on the welfare effects of crowd gates in the milking parlor, although there has been research on how best to manage cow flow in automatic milking systems (for review see Jacobs and Siegford, 2012). The topic of cross-sucking in calves has received some interest, with the first paper in our search being Kopp et al. (1986). Interestingly, Albright (1983), and to some degree Fox (1983), argued that individual housing is an appropriate solution to this problem due in part to perceived health benefits. We view individual housing as more of a "Band-Aid" solution (i.e., preventing the expression of the behavior but not the underlying motivation). More recent work has shown multiple problems associated with individual housing for calves and no added benefit in terms of health when compared with calves housed in small groups (for review see Costa et al., 2016). Other work published in JDS has also shown that the motivation to suck (including on pen mates, pen fixtures, and so on) is the result of underfeeding and unnatural feeding methods (i.e., buckets versus a teat; Jensen and Budde, 2006).

The article by Fox (1983) provides a summary of welfare issues (pages 2221-2223). This list includes concerns regarding increasing farm size and the resulting lack of individualized care. A recent review argued that there is no clear 1-way relationship between farm size and welfare (Robbins et al., 2016). For example, in a recent paper in JDS (Beggs et al., 2015), it was found that larger Australian herds had better trained workers (presumably favorable for welfare) but were also more likely to overstock their cows (presumably to the detriment of the cows). As summarized by Robbins et al. (2016), the cow-to-worker ratio is typically higher on larger farms, but "farm workers tend to be better paid, better trained, more specialized, and more satisfied" (page 5448) on these farms, perhaps compensating for the reduction in individualized care. Public concerns about cattle welfare are often rooted in the value of individualized care (Ventura et al., 2016a), and more work is required to directly assess the type and quality of care that is provided and how this relates to farm size.

Other issues raised by Fox (1983) included restriction of movement and social deprivation, as illustrated in the following quote regarding the housing of milkfed heifers and veal calves: "Continued confinement in small crates in which they cannot walk, run around, or interact freely with others is ethically questionable" (page 2222). As we described above, much work has now addressed the welfare issues associated with individual housing for calves.

Unfortunately, relatively little has been published in JDS specifically addressing the welfare issues associated with other types of confinement in dairy cattle. One obvious question is how long periods of housing in tiestalls may affect cow welfare. We suggest that many issues may be inherent to long periods of movement restriction, even if some improvements can be achieved by changes in tiestall design (Zurbrigg et al., 2005). The phasing out of tiestalls has already begun in some regions; for example, Norway banned new construction of this popular housing type in 2004, and a complete ban takes effect in 2023. The welfare impact of other types of restriction, including routine restriction of cows in head lockers for management and health procedures, is largely unknown.

A still contentious issue raised by Fox (1983) is that of cow-calf separation. Unfortunately, we could not find a single empirical paper published in JDS that directly addressed the welfare issues associated with this practice. This is an unfortunate gap given that we now know that that separation of cow and calf is an important area of public concern (Ventura et al., 2013; Hötzel et al., 2017). Another contentious and largely unresolved issue raised by Fox (1983) is the fate of bull calves that are often low-value by-products of dairy production.

The issues raised by Albright (1983) fall in some aspect or another into the biological functioning and health construct of animal welfare. In contrast, Fox (1983) was clearly also concerned about a lack of naturalness and negative affective states. More progress has been made on the biological issues, perhaps because welfare improvements in this domain often are associated with production benefits. For example, reductions in lameness benefit both the cow and the farmer's bottom line. The lack of progress on issues relating to naturalness and affective states may be attributable to a lack of research funding for this type of work. As noted by Albright (1987), "very little organized U.S. research on dairy animal welfare is underway"; the same could be said of the situation today. A significant portion of agricultural research is sponsored by corporations and thus is more focused on production and product testing 
than on general benefit to the dairy industry or broader society (see von Keyserlingk et al., 2013).

Our review shows that of the 9,190 publications with US-based corresponding authors since 1983, only $0.7 \%$ address the topic of animal welfare. In contrast, of the 7,576 publications with non-US-based corresponding authors over the same time period, $2.3 \%$ address the topic of welfare and a greater than 3-fold higher proportion of publications related to animal welfare. Thus, scientific guidance on the topic of animal welfare in the United States is largely dependent on the research and advice provided by scientists working outside of the United States (including the authors of the current review).

From the section above we can conclude that there is some basis for pride in the progress made within the journal to address priority issues in dairy welfare but that there are also areas where little or no progress has been made. We turn to some of these in the next section.

\section{FUTURE DIRECTIONS}

Below we speculate on what the future may hold for dairy cattle welfare research. We have organized this section in terms of the time horizon (short, medium, and long term) over which we believe that most progress will occur. Whether acceptable solutions are found over these periods will depend on resources, including funding, the availability of qualified individuals who are able to take a leadership role, and the continued interest and enthusiasm of stakeholders, including the public, producers, and industry professionals.

\section{Short Term}

In the short term (over the next decade especially), the dairy industry must work to implement proven science-based welfare solutions. This includes implementing pain control protocols for procedures such as dehorning (Stafford and Mellor, 2011), eliminating tail docking (Sutherland and Tucker, 2011), and providing calves more milk (Khan et al., 2011) and social housing (Costa et al., 2016).

There is also an immediate need to develop a scientific basis for new policies and practices regarding other well-recognized welfare issues. This includes the care, handling, and slaughter of surplus calves (predominantly bull calves) and downer cows. In some cases, we require new research (e.g., to identify practices that result in better recovery by downer cows; see Poulton et al., 2016; Stojkov et al., 2016). In other cases, the development of systems that help prevent the prob- lem are required (e.g., the use of sexed semen for the production of replacement heifers and cross-breeding with beef breeds to create high-value calves that can be reared humanely for beef; see Barkema et al., 2015).

In the short term there is also a need to study not just the dairy animal but also the humans who decide how cattle are to be cared for (farmers), those who advise farmers (e.g., veterinarians and dairy industry specialists), those who buy the dairy products (consumers), and those who ultimately decide what farming systems and associated management practices will be tolerated within their community (citizens; e.g., Smith et al., 2008). Specifically, we urge new work to assess public expectations for dairy farming (e.g., Cardoso et al., 2016) and perceived barriers to changing practices on farms (Weary et al., 2016) as well as understanding the role of dairy professionals in facilitating change on farms (Ventura et al., 2016b). This focus on the social as well as the natural sciences has been helpful for other areas of dairy science; in particular, we note the work on understanding barriers to changing practices in relation to mastitis control (e.g., Swinkels et al., 2015). Specifically, we hope that within 10 yr JDS will have a section devoted to work in the social sciences that embraces all aspects of dairy production.

\section{Medium Term}

Over the medium term (likely continuing for at least the next $20 \mathrm{yr}$ ), the dairy scientist community will continue to develop research-based solutions to health issues that affect many animals and cause considerable suffering. Key examples include the high rates of disease in transition cows and milk-fed calves. One special concern is lameness in dairy cattle because of the high prevalence and long duration of cases as well as the pain that cows experience. Indeed, we call for more research to better understand the effects of other important dairy cattle diseases, particularly during the transition from pregnancy to lactation, including mastitis and metritis, and the pain and malaise that affected cattle feel (Weary et al., 2009). We also see much room for the social sciences to help identify barriers to implementing proven welfare solutions on farms with regards to culling decisions and timely euthanasia.

\section{Long Term}

Over the longer term (likely continuing for at least the next $50 \mathrm{yr}$ ), scientists and professionals working within the dairy industry must also show the courage and innovation necessary to develop solutions that address societal expectations. We suggest that there will 
be at least 2 urgent priorities for the development and implementation of welfare-friendly practices: pasture access and cow-calf rearing.

As we outlined previously, we have found that both farmers and people outside of the dairy industry see pasture access as an important component of high-welfare dairy systems (Cardoso et al., 2016; Ventura et al., 2016a; Hötzel et al., 2017), but farmers often perceive barriers to implementing pasture access on their farms (Schuppli et al., 2014). Moreover, what is best from the cow's perspective may not always agree with public or even industry perspectives, so having a research basis that underpins recommendations is especially important. For example, although some may feel that pasture is always better for cows, research has shown that cows will often choose to come inside a well-designed and well-managed barn, especially to avoid direct sunlight when temperatures are high (Legrand et al., 2009) and during inclement weather (Charlton et al., 2013). Thus, we see the need for new research on systems based on free-choice access between well-managed indoor and outdoor facilities. These will allow cows to vary their choices depending on conditions and will allow different individuals to express their own idiosyncratic preferences. We also call for new work examining a range of different types of outdoor access. We have found that cows will often choose to consume a well-formulated mixed diet inside the barn rather than graze (Chapinal et al., 2010), meaning that outdoor systems may not need to be grass based or could take advantage of hardy, slow-growing grass varieties designed to provide a comfortable lying and standing surface rather than an important source of nutrients.

There appears to be little public support for the standard management practice of cow-calf separation (United States: Ventura et al., 2013; Brazil: Hötzel et al., 2017; United States and Germany: Busch et al., 2017). Very little research is available to either justify this practice or provide alternatives. The few studies to date suggest that the practice increases the risk of postpartum disease in early lactation (e.g., Krohn et al., 1990). Moreover, the available health data indicate that despite early separation of cow and calf, morbidity and mortality rates are high for both the calf (see review by Costa et al., 2016) and the transition cow (McConnel et al., 2008). On the basis of this evidence, critics could argue that separation may be detrimental to the health and welfare of both the cow and the calf. Some initial guidance on possible solutions may be found in the few studies done on the use of nurse cows (e.g., Loberg and Lidfors, 2001), Bos indicus systems that allow the dam some contact with her calf (Das et al., 2000), and recent work by Johnsen et al. (2015a,b) on keeping calves with access to the dam and a supplementary milk supply. Given the complexity of the issue, including the difficulty in developing practical methods that are economically sustainable for farmers, much new research will be required.

\section{CONCLUSIONS}

Animal welfare is a relatively new area of application; the first papers directly focused on this topic were published in JDS in 1983. Over the last $30 \mathrm{yr}$, JDS publications have made important contributions to animal welfare issues such as tail docking, providing calves more milk, and pain mitigation during dehorning, but little has been published on other important issues (e.g., cow-calf separation). The field of animal behavior has played a central role in many of these studies. Animal welfare is a socially mandated science requiring input from all stakeholders, including the public. Research in the social sciences can help document the shared and divergent values of different stakeholders, beliefs regarding the available evidence, and barriers to implementing change, all of which are needed to develop practices that resonate with societal values.

\section{ACKNOWLEDGMENTS}

A special thank you to Alexi Thompson [Animal Welfare Program, University of British Columbia (UBC), Vancouver, BC, Canada] for help with literature searches, the development of the figures, and comments on the manuscript. We also thank current and former students Christine Sumner (Animal Welfare Program, UBC) and Katelyn Mills (Animal Welfare Program, UBC) as well as Jesse Robbins (Animal Welfare Program, UBC), Jeffrey Spooner (Ottawa, ON, Canada), Katy Proudfoot (The Ohio State University, Columbus), and Trevor DeVries (University of Guelph, Guelph, ON, Canada) for their comments on an earlier version of the manuscript. The authors are supported by Canada's Natural Sciences and Engineering Research Council Industrial Research Chair Program with industry contributions from the Dairy Farmers of Canada (Ottawa, ON, Canada), British Columbia Dairy Association (Burnaby, BC Canada), Westgen Endowment Fund (Milner, BC, Canada), Intervet Canada Corporation (Kirkland, QC, Canada), Novus International Inc. (Oakville, ON, Canada), Zoetis (Kirkland, QC, Canada), BC Cattle Industry Development Fund (Kamloops, BC, Canada), Alberta Milk (Edmonton, AB, Canada), Valacta (St. Anne-de-Bellevue, QC, Canada), and CanWest DHI (Guelph, ON, Canada). 


\section{REFERENCES}

Albright, J. L. 1983. Status of animal welfare awareness of producers and direction of animal welfare research in the future. J. Dairy Sci. 66:2208-2220.

Albright, J. L. 1987. Dairy animal welfare: Current and needed research. J. Dairy Sci. 70:2711-2731.

Albright, J. L. 1993. Feeding behavior in dairy cattle. J. Dairy Sci. 76:485-498.

Baile, C. A., and F. H. Martin. 1971. Hormones and amino acids as possible factors in the control of hunger and satiety in sheep. J. Dairy Sci. 54:897-905.

Barkema, H. W., M. A. G. von Keyserlingk, J. P. Kastelic, T. J. G. M. Lam, C. Luby, J.-P. Roy, S. J. Leblanc, G. P. Keefe, and D. F. Kelton. 2015. Invited review: Changes in the dairy industry affecting dairy cattle health and welfare. J. Dairy Sci. 98:7426-7445.

Barrier, A. C., and M. J. Haskell. 2011. Calving difficulty in dairy cows has a longer effect on saleable milk yield than on estimated milk production. J. Dairy Sci. 94:1804-1812.

Beggs, D. S., A. D. Fisher, E. C. Jongman, and P. E. Hemsworth. 2015. A survey of Australian dairy farmers to investigate animal welfare risks associated with increasing scale of production. J. Dairy Sci. 98:5330-5338.

Boissy, A., G. Manteuffel, M. B. Jensen, R. O. Moe, B. Spruijt, L. J. Keeling, C. Winckler, B. Forkman, I. Dimitrov, J. Langbein, M. Bakken, I. Veissier, and A. Aubert. 2007. Assessment of positive emotions in animals to improve their welfare. Physiol. Behav. 92:375-397.

Brambell, F. W. R. 1965. Report of the Technical Committee to Enquire into the Welfare of Animals Kept Under Intensive Livestock Husbandry Systems. Her Majesty's Stationery Office, London, United Kingdom.

Busch, G., D. M. Weary, A. Spiller, and M. A. G. von Keyserlingk. 2017. American and German attitudes towards cow-calf separation on dairy farms. PLoS One 12(3):e0174013.

California Legislative Information. 2009. SB-135 Animal abuse: Cattle: Tail docking. Accessed Jun. 6, 2017. http://leginfo.legislature.ca .gov/faces/billNavClient.xhtml?bill_id=200920100SB135.

Cardoso, C. S., M. J. Hötzel, D. M. Weary, J. A. Robbins, and M. A. G. von Keyserlingk. 2016. Imaging the ideal dairy farm. J. Dairy Sci. 99:1663-1671.

Chapinal, N., C. Goldhawk, A. M. de Passilé, M. A. G. von Keyserlingk, D. M. Weary, and J. Rushen. 2010. Overnight access to pasture does not reduce milk production or feed intake in dairy cattle. Livest. Sci. 129:104-110.

Charlton, G. L., S. M. Rutter, M. East, and L. A. Sinclair. 2011. Effects of providing total mixed rations indoors and on pasture on the behavior of lactating dairy cattle and their preference to be indoors or on pasture. J. Dairy Sci. 94:3875-3884.

Charlton, G. L., S. M. Rutter, M. East, and L. A. Sinclair. 2013. The motivation of dairy cows for access to pasture. J. Dairy Sci. 96:4387-4396.

Costa, J. H. C., M. A. G. von Keyserlingk, and D. M. Weary. 2016. Invited review: Effects of group housing of dairy calves on behavior, cognition, performance and health. J. Dairy Sci. 99:2453-2467.

Das, S. M., I. Redbo, and H. Wiktorsson. 2000. Effect of age of calf on suckling behaviour and other behavioural activities of Zebu and crossbred calves during restricted suckling periods. Appl. Anim. Behav. Sci. 67:47-57.

Dawkins, M. S. 1988. Behavioural deprivation: A central problem in animal welfare. Appl. Anim. Behav. Sci. 20:209-225. https://doi .org/10.1016/0168-1591(88)90047-0.

Dean Foods Inc. 2012. Animal welfare. Accessed Jun. 5, 2017. http:// responsibility.deanfoods.com/social-responsibility/animal-welfare/.

DeVries, T. J., M. A. G. von Keyserlingk, and K. A. Beauchemin. 2003. Short communication: Diurnal feeding pattern of lactating dairy cows. J. Dairy Sci. 86:4079-4082.

DFC-NFACC (Dairy Farmers of Canada-National Farm Animal Care Committee). 2009. Code of practice for the care and handling of dairy cattle. Accessed Jun. 6, 2017. http://www.nfacc.ca/pdfs/ codes/Dairy\%20Code\%20of\%20Practice.pdf.
Drackley, J. K. 1999. Biology of dairy cows during the transition period: The final frontier? J. Dairy Sci. 82:2259-2273.

Duncan, I. J. 2004. A concept of welfare based on feelings. Pages 85-101 in The Well-Being of Farm Animals: Challenges and Solutions. In G. J. Benson and B. E. Rollin, ed. Blackwell, Ames, IA.

Eicher, S. D., J. L. Morrow-Tesch, J. L. Albright, J. W. Dailey, C. R. Young, and L. H. Stanker. 2000. Tail-docking influences on behavioral, immunological, and endocrine responses in dairy heifers. J. Dairy Sci. 83:1456-1462.

Faulkner, P. M., and D. M. Weary. 2000. Reducing pain after dehorning in dairy calves. J. Dairy Sci. 83:2037-2041.

FAWC (Farm Animal Welfare Council). 1992. FAWC updates the five freedoms. Vet. Rec. 131:357

Fox, M. W. 1983. Animal welfare and the dairy industry. J. Dairy Sci. 66:2221-2225.

Fraser, D., D. M. Weary, E. A. Pajor, and B. N. Milligan. 1997. A scientific conception of animal welfare that reflects ethical concerns. Anim. Welf. 6:187-205.

Graf, G. C., and W. E. Petersen. 1953. Changes in respiration and heart rates, body temperatures, plasma lactic acid levels and plasma creatinine levels caused by stress in dairy cattle. J. Dairy Sci. 36:1036-1048

Harrison, R. 1964. Animal Machines: An Exposé of "Factory Farming'" and Its Danger to the Public. Ballantine Books, New York, NY.

Heinrich, A., T. F. Duffield, K. D. Lissemore, E. J. Squires, and S. T. Millman. 2009. The impact of meloxicam on postsurgical stress associated with cautery dehorning. J. Dairy Sci. 92:540-547.

Hoeben, D., C. Burvenich, P. J. Eppard, J. C. Byatt, and D. L. Hard. 1999. Effect of bovine somatotropin on neutrophil functions and clinical symptoms during Streptococcus uberis mastitis. J. Dairy Sci. 82:1465-1481.

Hötzel, M. J., C. S. Cardoso, A. Roslindo, and M. A. G. von Keyserlingk. 2017. Citizens' views on the practices of zero-grazing and cow-calf separation in the dairy industry: Does providing information increase acceptability? J. Dairy Sci. 100:4150-4160.

Huzzey, J. M., T. J. DeVries, P. Valois, and M. A. G. von Keyserlingk. 2006. Stocking density and feed barrier design affect feeding and social behavior of dairy cattle. J. Dairy Sci. 89:126-133.

Ingvartsen, K. L., and J. B. Andersen. 2000. Integration of metabolism and intake regulation: A review focusing on periparturient animals. J. Dairy Sci. 83:1573-1597.

Jacobs, J. A., and J. M. Siegford. 2012. Invited review: The impact of automatic milking systems on dairy cow management, behavior, health, and welfare. J. Dairy Sci. 95:2227-2247.

Jensen, M. B., and M. Budde. 2006. The effects of milk feeding method and group size on feeding behavior and cross-sucking in grouphoused dairy calves. J. Dairy Sci. 89:4778-4783.

Johnsen, J. F., A. Beaver, C. M. Mejdell, A. M. de Passillé, J. Rushen, and D. M. Weary. 2015a. Providing supplementary milk to suckling dairy calves improves performance at separation and weaning. J. Dairy Sci. 98:4800-4810.

Johnsen, J. F., A. M. de Passille, C. M. Mejdell, K. E. Bøe, A. M. Grøndahl, A. Beaver, J. Rushen, and D. M. Weary. 2015b. The effect of nursing on the cow-calf bond. Appl. Anim. Behav. Sci. 163:50-57.

Khan, M. A., D. M. Weary, and M. A. G. von Keyserlingk. 2011. Invited review: Effects of milk ration on solid feed intake, weaning, and performance in dairy heifers. J. Dairy Sci. 94:1071-1081.

Kopp, M. B., T. H. Friend, and G. R. Dellmeier. 1986. Effect of feeding method on nonnutritive oral activities in Holstein calves. J. Dairy Sci. 69:3094-3099.

Krohn, C. B., L. Jonasen, and L. Munksgaard. 1990. Cow-calf relations. 2: The effect of 0 vs. 5 days suckling on behaviour, milk production and udder health of cows in different stabling. Report No. 678. National Institute of Animal Science, Foulum, Denmark.

LeBlanc, S. J., K. D. Lissemore, D. F. Kelton, T. F. Duffield, and K. E. Leslie. 2006. Major advances in disease prevention in dairy cattle. J. Dairy Sci. 89:1267-1279.

Legrand, A. L., M. A. G. von Keyserlingk, and D. M. Weary. 2009. Preference and usage of pasture versus free-stall housing by lactating dairy cattle. J. Dairy Sci. 92:3651-3658. 
Leruste, H., M. Brscic, G. Cozzi, B. Kemp, M. Wolthuis-Fillerup, B. J. Lensink, E. A. M. Bokkers, and C. G. van Reenen. 2014. Prevalence and potential influencing factors of non-nutritive oral behaviors of veal calves on commercial farms. J. Dairy Sci. 97:7021-7030.

Loberg, J., and L. Lidfors. 2001. Effect of milk flow rate and presence of a floating nipple on abnormal sucking between dairy calves. Appl. Anim. Behav. Sci. 72:189-199.

Mason, G. J. R. 2008. Stereotypic Animal Behavior: Fundamentals and Applications to Welfare. CAB International, Wallingford, United Kingdom.

McConnel, C. S., J. E. Lombard, B. A. Wagner, and F. B. Garry. 2008. Evaluation of factors associated with increased dairy cow mortality on United States dairy operations. J. Dairy Sci. 91:1423-1432.

Mench, J. A. 2008. Farm animal welfare in the U.S.-Farming practices, research, education, regulation and assurance programs. Appl. Anim. Behav. Sci. 113:298-312.

Ministry for Rural Affairs - Government Offices of Sweden. 2009. The Animal Welfare Act. Ministry for Rural Affairs, Government Offices of Sweden, Stockholm, Sweden.

Munksgaard, L., A. M. de Passillé, J. Rushen, K. Thodberg, and M. B. Jensen. 1997. Discrimination of people by dairy cows based on handling. J. Dairy Sci. 80:1106-1112.

Natzke, R. P., D. R. Bray, and R. W. Everett. 1982. Cow preference for free stall surface material. J. Dairy Sci. 65:146-153.

NFACC (National Farm Animal Care Council). 2014. NFACC code of practice development process. Accessed Jun. 6, 2017. http://www .nfacc.ca/resources/codes-of-practice/NFACC_Code_process_Jan 2014.pdf.

NMPF (National Milk Producers Federation). 2016. Animal care reference manual. Accessed Jun. 6, 2017. http:// www.nationaldairyfarm .com/sites/default/files/Version-3-Manual.pdf.

Poulton, P. J., A. L. Vizard, G. A. Anderson, and M. F. Pyman. 2016. High-quality care improves outcome in recumbent dairy cattle. Aust. Vet. J. 94:173-180.

Robbins, J. A., M. A. G. von Keyserlingk, D. Fraser, and D. M. Weary. 2016. Invited review: Farm size and animal welfare. J. Anim. Sci. 94:5439-5455.

Saputo Inc. 2015. Animal welfare policy. Accessed Jun. 5, 2017. http://www.saputo.com/en/Our-Promise/Responsible-Sourcing/ Animal-Welfare.

Schreiner, D. A., and P. L. Ruegg. 2002. Responses to tail docking in calves and heifers. J. Dairy Sci. 85:3287-3296.

Schuppli, C. A., M. A. G. von Keyserlingk, and D. M. Weary. 2014. Access to pasture for dairy cows: Responses from an on-line engagement. J. Anim. Sci. 92:5185-5192.

Seath, D. M., C. Branton, and A. H. Groth. 1945. Effect of feeding iodinated casein on production and health of milking cows. J. Dairy Sci. 7:509-517.

Skarstad, G. A., and S. O. Borgen. 2007. Norwegian cattle farmers' view on animal welfare. Welfare Quality Reports 3.1. Norwegian Agricultural Economics Research Institute, Oslo, Norway.

Smith, J. M., R. L. Parsons, K. Van Dis, and G. N. Matiru. 2008. Love thy neighbor - But does that include a six hundred eighty-four cow dairy operation? A survey of community perceptions. J. Dairy Sci. 91:1673-1685.

Somers, J. G. C. J., K. Frankena, E. N. Noordhuizen-Stassen, and J. H. M. Metz. 2003. Prevalence of claw disorders in Dutch dairy cows exposed to several floor systems. J. Dairy Sci. 86:2082-2093.

Stafford, K. J., and D. J. Mellor. 2011. Addressing the pain associated with disbudding and dehorning in cattle. Appl. Anim. Behav. Sci. 135:226-231.

Stojkov, J., D. M. Weary, and M. A. G. von Keyserlingk. 2016. Nonambulatory cows: Duration of recumbency and nursing care affect flotation therapy outcome. J. Dairy Sci. 99:2076-2085

Sutherland, M. A., and C. B. Tucker. 2011. The long and short of it: A review of tail docking in farm animals. Appl. Anim. Behav. Sci. 135:179-191.

Swinkels, J. M., A. Hilkens, V. Zoche-Golob, V. Krömker, M. Buddiger, J. Jansen, and T. J. G. M. Lam. 2015. Social influences on the duration of antibiotic treatment of clinical mastitis in dairy cows. J. Dairy Sci. 98:2369-2380.
Telezhenko, E., C. Bergsten, M. Magnusson, M. Ventorp, and C. Nilsson. 2008. Effect of different flooring systems on weight and pressure distribution on claws of dairy cows. J. Dairy Sci. 91:18741884.

Telezhenko, E., L. Lidfors, and C. Bergsten. 2007. Dairy cow preferences for soft or hard flooring when standing or walking. J. Dairy Sci. 90:3716-3724.

Thomsen, P. T., K. Dahl-Pedersen, and H. E. Jensen. 2012. Necropsy as a means to gain additional information about causes of dairy cow deaths. J. Dairy Sci. 95:5798-5803.

USDA. 1873. Twenty-Eight Hour Law (amended 1994). Accessed May 30, 2017. https://www.nal.usda.gov/awic/twenty-eight-hour-law.

USDA. 1958. The Humane Methods of Slaughter Act. Accessed May 30, 2017. https://www.nal.usda.gov/awic/humane-methods -slaughter-act.

Valníčková, B., I. Stěhulová, R. Šárová, and M. Špinka. 2015. The effect of age at separation from the dam and presence of social companions on play behavior and weight gain in dairy calves. J. Dairy Sci. 98:5545-5556.

Ventura, B. A., C. Schuppli, M. A. G. von Keyserlingk, and D. M. Weary. 2013. Views on contentious practices in dairy farming: The case of early cow-calf separation. J. Dairy Sci. 96:6105-6116.

Ventura, B. A., M. A. G. von Keyserlingk, H. Wittman, and D. M. Weary. 2016a. What difference does a visit make? Changes in animal welfare perceptions after interested citizens tour a dairy farm. PLoS One 11:e154733. https://doi.org/10.1371/journal.pone .0154733 .

Ventura, B. A., D. M. Weary, and M. A. G. von Keyserlingk. 2016b. Veterinary perspectives on cattle welfare challenges and solutions. Livest. Sci. 193:95-103.

von Keyserlingk, M. A. G., and M. J. Hötzel. 2015. The ticking clock: Addressing farm animal welfare in emerging countries. J. Agric. Environ. Ethics 28:179-195.

von Keyserlingk, M. A. G., N. P. Martin, E. Kebreab, C. J. Sniffen, J. P. Harner III, A. D. Wright, and S. I. Smith. 2013. Invited review: Sustainability of the US dairy industry. J. Dairy Sci. 96:5405-5425.

von Keyserlingk, M. A. G., J. Rushen, A. M. B. de Passillé, and D. M. Weary. 2009. Invited review: The welfare of dairy cattle-Key concepts and the role of science. J. Dairy Sci. 92:4101-4111.

Weary, D. M., P. Droege, and V. A. Braithwaite. 2017. Behavioura evidence of felt emotions: Approaches, inferences and refinements. Adv. Stud. Behav. 49:27-48.

Weary, D. M., J. M. Huzzey, and M. A. G. von Keyserlingk. 2009. Board-invited review: Using behavior to predict and identify ill health in animals. J. Anim. Sci. 87:770-777.

Weary, D. M., B. A. Ventura, and M. A. G. von Keyserlingk. 2016. Societal views and animal welfare science: Understanding why the modified cage may fail and other stories. Animal 10:309-317.

Weary, D. M., and M. A. G. von Keyserlingk. 2017. Public concerns about dairy-cow welfare: How should the industry respond? Anim. Prod. Sci. 57:1201-1209. https://doi.org/10.1071/AN16680.

Wells, S. J., S. L. Ott, and A. H. Seitzinger. 1998. Key health issues for dairy cattle - New and old. J. Dairy Sci. 81:3029-3035.

Westin, R., A. Vaughan, and A. M. de Passille. 2016. Lying times of lactating cows on dairy farms with automatic milking systems and the relation to lameness, leg lesions, and body condition score. J. Dairy Sci. 99:551-561.T. J. DeVriesE. A. PajorD. PellerinJ. M. SiegfordE. VasseurJ. Rushen

Wise, G. H., and G. W. Anderson. 1939. Factors affecting the passage of liquids into the rumen of the dairy calf. I. Method of administering liquids: Drinking from open pail verses sucking through a rubber nipple. J. Dairy Sci. 22:697-705.

Wohlt, J. E., M. E. Allyn, P. K. Zajac, and L. S. Katz. 1994. Cortisol increases in plasma of Holstein heifer calves, from handling and method of electrical dehorning. J. Dairy Sci. 77:3725-3729.

Wolf, C. A., and G. T. Tonsor. 2017. Cow welfare in the U.S. dairy industry: Willingness-to-pay and willingness-to-supply. J. Agric. Resour. Econ. 42:164-179.

Zurbrigg, K., D. Kelton, N. Anderson, and S. Millman. 2005. Tie-stall design and its relationship to lameness, injury, and cleanliness on 317 Ontario dairy farms. J. Dairy Sci. 88:3201-3210. 


\section{APPENDIX}

Table A1. A timeline of the key contributions to the field of animal welfare

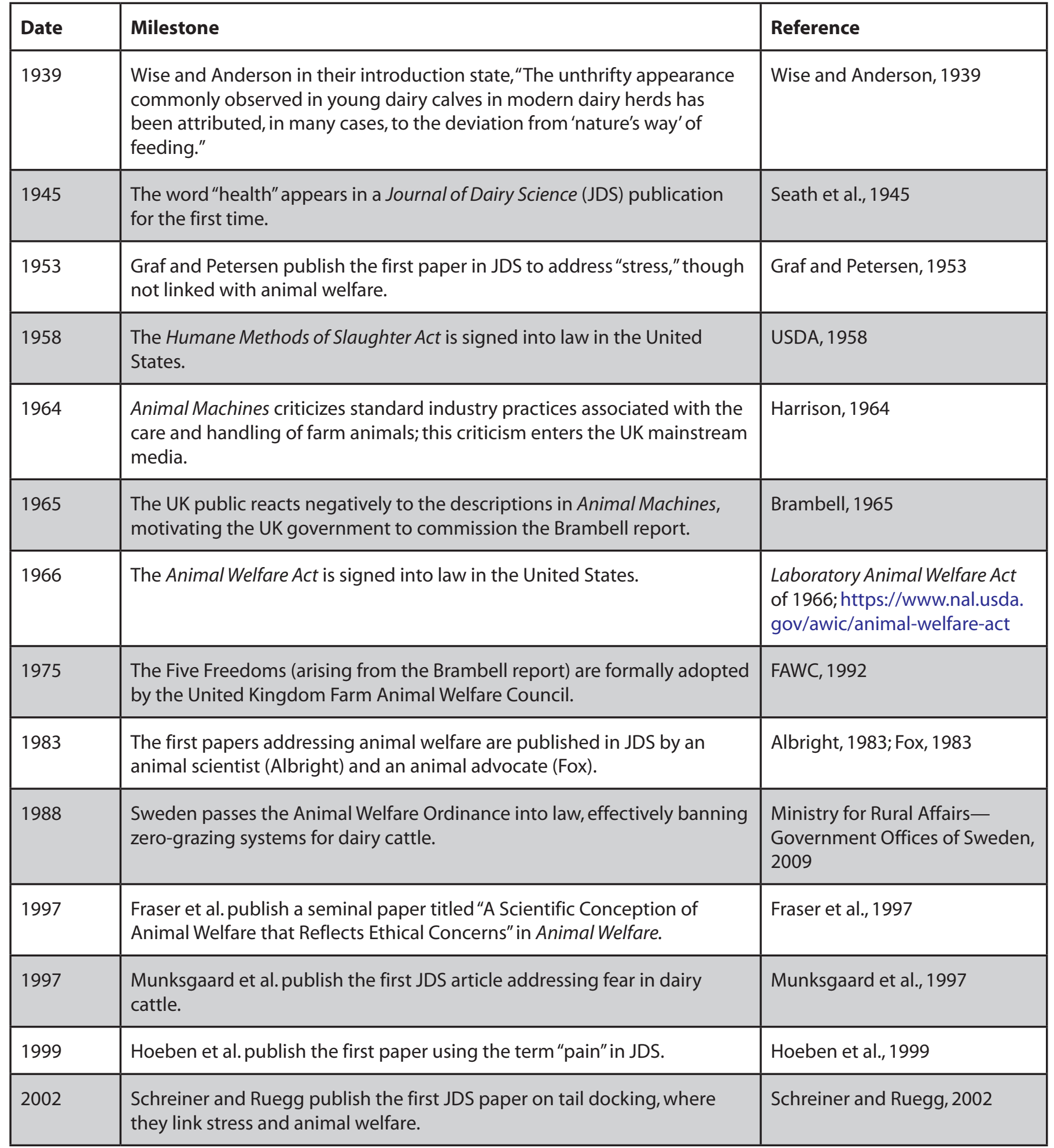


Table A1 (Continued). A timeline of the key contributions to the field of animal welfare

\begin{tabular}{|l|l|l|}
\hline Date & Milestone & Reference \\
\hline 2004 & $\begin{array}{l}\text { Norway bans new construction of tiestall housing (with a complete ban by } \\
\text { 2024). }\end{array}$ & Skarstad and Borgen, 2007 \\
\hline 2008 & Smith et al. publish the first social science paper in JDS. & Smith et al., 2008 \\
\hline 2009 & State of California bans tail docking of cattle. & $\begin{array}{l}\text { California Legislative } \\
\text { Information, 2009 }\end{array}$ \\
\hline 2009 & $\begin{array}{l}\text { Dairy Farmers of Canada and the US-based National Federation of Milk } \\
\text { Producers publish industry guidelines for care and handling of dairy cattle. }\end{array}$ & DFC-NFACC, 2009; NMPF, 2016 \\
\hline 2009 & $\begin{array}{l}\text { von Keyserlingk et al. publish “The Welfare of Dairy Cattle-Key Concepts } \\
\text { and the Role of Science” in JDS. }\end{array}$ & von Keyserlingk et al., 2009 \\
\hline 2009 & The 50th paper addressing animal welfare is published in JDS. & von Keyserlingk et al., 2009 \\
\hline 2012 & The 100th paper addressing animal welfare is published in JDS. & Thomsen et al., 2012 \\
\hline Jan. 2016 & The 200th article addressing animal welfare is published in JDS. & Westin et al., 2016 \\
\hline
\end{tabular}

